\title{
Sarcocystosis in South American camelids: The state of play revisited
}

\author{
Muhammad A. Saeed', Mohammed H. Rashid', Jane Vaughan² and Abdul Jabbarr*
}

\begin{abstract}
Members of the genus Sarcocystis (Apicomplexa: Sarcocystidae) are intracellular protozoan parasites that infect a wide range of domestic and wild animals, resulting in economic losses in production animals worldwide. Sarcocystis spp. have indirect life-cycles where canids and felids serve as main definitive hosts while a range of domestic and wild animals serve as intermediate hosts, including South American camelids (SACS) such as alpacas, llamas and guanacos. These animals primarily occur in South American countries on Andean, elevated plains but in recent years, alpacas and llamas have become emerging animal industries in other parts of the world such as Australia, Europe and the USA due to their highquality fiber, meat and hides. For instance, alpaca meat is becoming popular in many parts of the world due to its lower cholesterol content than other red meat, thereby it has the potential of a valuable product for both local and international markets. However, SAC meat can be degraded and/or even condemned due to the presence of macroscopic sarcocysts in skeletal muscles, leading to significant economic losses to farmers. The infection is generally asymptomatic, though highly pathogenic or even fatal Sarcocystis infections have also been reported in alpacas and llamas. Despite the economic importance of sarcocystosis in SACs, little is known about the life-cycle of parasites involved, disease transmission, epidemiology, pathogenesis, diagnosis, control and public health significance. This review article provides an in-depth analysis of the existing knowledge on the taxonomy, epidemiology, clinicopathology and diagnosis of Sarcocystis in SACs, highlights knowledge gaps and proposes future areas of research that could contribute to our better understanding of sarcocystosis in these animals.
\end{abstract}

Keywords: Sarcocystosis, Sarcocystis, Alpaca, Llama, Guanaco, Vicuna

\section{Background}

Sarcocystosis is a parasitic disease caused by intracellular protozoan parasites belonging to the genus, Sarcocystis (Apicomplexa: Sarcocystidae). There are more than 200 species of Sarcocystis recognized [1] that infect a wide array of domestic and wild animals worldwide, causing significant health and economic losses [1,2]. Members of the genus Sarcocystis have indirect life-cycles where definitive hosts such as carnivores or omnivores (e.g. humans), reptiles and raptorial birds become infected following ingestion of infective stages of parasites and then following sexual development, excrete oocysts/sporocysts into the environment that could infect intermediate hosts. In intermediate hosts, including herbivorous animals, humans, nonhuman primates, birds, reptiles and carnivores, parasites enter

\footnotetext{
*Correspondence: jabbara@unimelb.edu.au

'Department of Veterinary Biosciences, Faculty of Veterinary and Agricultural Sciences, The University of Melbourne, Werribee, Victoria 3030, Australia Full list of author information is available at the end of the article
}

endothelial cells where they undergo multiple generations of merogony (asexual development) and sarcocysts (microscopic or macroscopic depending on the species involved) develop primarily in skeletal muscles of the tongue, neck, diaphragm, and legs and cardiac muscles $[1,3,4]$, though they have also been found in smooth muscles of the intestine and central nervous system $[1,5]$.

South American camelids (SACs), include alpacas (Vicugna pacos), llamas (Lama glama), vicunas (Vicugna vicugna) and guanacos (Lama guanicoe) and make up a total population of at least seven million. They are widely distributed in South America, with alpacas, llamas and vicunas ranging from southern Ecuador to northern Chile with high densities in Bolivia and Peru, and guanacos are found across southern Argentina and Chile [6-8]. Alpacas and llamas are domesticated farm animals while guanacos and vicunas are wild species. The greatest numbers of SACs are raised by Andean families, playing a crucial role in their socioeconomic status as these animals are a good 
source of meat, hides and quality fiber [7-9]. Given that SACs possess physiological adaptations to high altitude and arid conditions, they are suitable for commercial livestock farming not only at high altitudes with freezing temperatures but also in regions of low rainfall - a distinguishing feature from other domestic livestock $[6,9]$. The consumption of alpaca meat is increasing in developed countries as it possesses lower fat and cholesterol than beef, sheep and goat meat which potentially makes it a highly valuable product for both local and international markets [10]. Due to their superior quality wool/fiber and meat, alpaca and llamas farming have become an emerging animal industry in many parts of the world, including Australia, Europe and the USA. For instance, Australia has one of the largest alpaca breeding herds in the world and also has the largest alpaca population (i.e. > 300,000) outside South America [9, 11]. However, SAC meat can be downgraded or condemned due to sarcocystosis and associated public health concerns $[8,12]$.

South American camelids serve as important intermediate hosts for Sarcocystis spp., with macroscopic sarcocysts $(2-7 \mathrm{~mm})$ appearing in various skeletal muscles of llamas and alpacas, thus rendering meat unfit for human consumption [1, 13, 14], and leading to economic losses $[6,15,16]$. Sarcocystis spp. usually cause subclinical infections in SACs, although fatal cases have also been reported $[17,18]$. Sarcocystosis is an emerging disease in SACs [19], however little is known about its pathology, transmission, life-cycle, economic importance and public health significance.

This article is aimed to provide a systematic overview of the current knowledge on the pathogenesis, epidemiology, taxonomy and diagnosis of Sarcocystis spp. infecting SACs. Furthermore, it highlights future areas of research that could contribute to our better understanding of sarcocystosis in alpacas and llamas.

\section{Taxonomy of Sarcocystis spp. in South American camelids}

Although both macroscopic (macrocysts) and microscopic (microcysts) sarcocysts have been reported in SACs (Table 1) [13, 14, 17, 18], it remained elusive until recently whether the two types of sarcocysts in SACs were caused by the same or different species of Sarcocystis. Thus, various names have been proposed to describe sarcocysts in SACs, resulting in considerable confusion regarding the nomenclature of Sarcocystis spp. infecting alpacas, guanacos and llamas.

The first macroscopic sarcocyst in SACs was reported from a llama about a century ago and the parasite was named as Sarcocystis aucheniae, though no further details were provided [20]. Decades later, sarcocysts were observed in a guanaco and the parasite was named as $S$. tilopodi, based on its presence in a different camelid host rather than morphological differences [21]. Gorman et al. [22] experimentally infected dogs and cats with macroscopic sarcocysts from guanacos and found that only dogs excreted parasites (sporocysts) in their feces. These authors proposed that the parasites should be called as S. guanicoecanis and S. lamacanis in guanacos and llamas, respectively; however, no morphological differences to differentiate these sarcocysts were described. Subsequently, it was proposed that macroscopic and microscopic sarcocyst-forming species of Sarcocystis in alpacas and llamas should be called $S$. aucheniae and $S$. lamacenis, respectively, although no explanation for this proposal was provided [6].

Until recently, various names, including $S$. aucheniae, S. lamacanis and S. lamacenis had been used in different studies [15, 23, 24]. However, recently Dubey et al. [1] proposed that $S$. aucheniae was the only valid name (as per standard nomenclature) for the Sarcocystis species that forms macroscopic sarcocysts in llamas and alpacas. Recently, microscopic cysts from alpaca, llama, and guanacos from South American countries were described and the parasite was named as S. masoni [14]. Hence,

Table 1 Morphology of Sarcocystis spp. in South American camelids

\begin{tabular}{|c|c|c|c|c|c|}
\hline Species of Sarcocystis ${ }^{a}$ & Type of tissue cyst & Host & Size of tissue cyst (mm) & Bradyzoite/ merozoite $(\mu \mathrm{m})$ & Reference \\
\hline \multirow[t]{5}{*}{ S. aucheniae } & \multirow[t]{5}{*}{ Macroscopic } & Llama & $4-5$ & na & [38] \\
\hline & & $\begin{array}{l}\text { Alpaca, llama, } \\
\text { guanaco }\end{array}$ & $2-7$ & $13-18 \times 3-5$ & [14] \\
\hline & & Guanaco & $2-7$ & $13-18 \times 3-5$ & [13] \\
\hline & & Llama & na & $17.7 \times 3.6$ & [16] \\
\hline & & Alpaca & $8 \times 3$ & na & [18] \\
\hline Sarcocystis sp. & & Alpaca & $0.4-0.8$ & $2-4$ & [17] \\
\hline S. masoni & Microscopic & $\begin{array}{l}\text { Alpaca, llama, } \\
\text { guanaco }\end{array}$ & $0.8 \times 0.035-0.095$ & $11-14 \times 2-3.5$ & [14] \\
\hline
\end{tabular}


based on the current morphological and molecular evidence, only two valid species of Sarcocystis, S. aucheniae and S. masoni, infect SACs that form macroscopic and microscopic sarcocysts, respectively. However, in this review, we have used the original names of Sarcocystis spp. as used by various authors (Tables 2 and 3 ) as it was not possible for us to decide which type of sarcocyst was S. aucheniae or S. masoni.

\section{Structure of sarcocysts found in SACs}

Both macroscopic and microscopic sarcocysts have been reported from SACs [13, 14, 17, 18]. Grossly, macroscopic sarcocysts appear as rice-sized and shaped cysts in various skeletal muscles (Fig. 1) of alpacas, guanacos and llamas while microscopic sarcocysts are commonly found in cardiac muscles of alpacas and llamas [13, 14]. Generally, a sarcocyst consists of a primary cyst wall which contains numerous villar protrusions. The ground substance is found at the base of villar protrusions which extends inside the cyst cavity to divide it into numerous compartments, containing metrocytes and merozoites/bradyzoites [1]. The structure of primary cyst wall is considered the most important criterion to classify Sarcocystis spp. [1, 25].

\section{Macroscopic sarcocysts (S. aucheniae)}

Macroscopic sarcocysts are 2-7 $\mathrm{mm}$ long, pale yellow in color and are surrounded by a dense $(50 \mu \mathrm{m}$ thick) secondary cyst wall. Schnieder et al. [26] described the first ultrastructure of macroscopic sarcocysts (S. aucheniae) isolated from llamas in Bolivia. Subsequently, several studies have described the ultrastructure of $S$. aucheniae macrocysts isolated from alpacas, llamas and guanacos from various countries $[13,14]$.

The cyst wall of a macroscopic sarcocyst can measure up to $10 \mu \mathrm{m}$ thick (including the ground substance layer) and is folded into surrounding muscle fibers to form cauliflower-like villar protrusions. Each villar protrusion contains numerous microfilaments or microtubules [26]. The villar protrusions measure approximately $3.0-4.5 \times 2.5-3.5 \mu \mathrm{m}$ in size and some of them harbor a conical cap. Each sarcocyst contains 10-15 million bradyzoites $(13-18 \times 3-5 \mu \mathrm{m})$ which are oval to elongated in shape and packed in sacs separated by septa. Each bradyzoite contains several micronemes (secretory organelles) and amylopectin granules, clustered in anterior and posterior halves, respectively $[13,14]$. Recent studies revealed

Table 2 Studies aimed at assessing the prevalence and epidemiology of Sarcocystis spp. using different diagnostic methods in South American camelids

\begin{tabular}{|c|c|c|c|c|c|c|}
\hline Species of Sarcocystis $^{a}$ & Host & Geographical location & Tissue examined & Method used & Percent prevalence (proportion) & Reference \\
\hline \multirow[t]{10}{*}{ S. aucheniae } & Llama & Argentina & Serum & ELISA & $36(183 / 507)$ & [8] \\
\hline & Llama & Argentina & Blood & PCR & na & [38] \\
\hline & $\begin{array}{l}\text { Alpaca, llama, } \\
\text { guanaco }\end{array}$ & Argentina, Peru & Skeletal muscle & $\begin{array}{l}\text { Ge, Mic, } \\
\text { TEM, PCR }\end{array}$ & na & [14] \\
\hline & Guanaco & Argentina & Skeletal muscle & Ge, TEM, PCR & $100(2 / 2)$ & [13] \\
\hline & Llama & Argentina & Serum & Ge, PCR & $100(3 / 3)$ & [16] \\
\hline & \multirow[t]{2}{*}{ Llama } & \multirow[t]{2}{*}{ Bolivia } & Skeletal muscle & Ge & $35(138 / 378)$ & \multirow[t]{2}{*}{ [12] } \\
\hline & & & Serum & ELISA & $45(171 / 378)$ & \\
\hline & Alpaca & Australia & Skeletal muscle & PCR & $100(1 / 1)$ & [27] \\
\hline & Alpaca & USA & Skeletal muscle & Ge, His, TEM & $100(1 / 1)$ & [18] \\
\hline & Llama & Bolivia & Skeletal muscle & Ge, Mic, TEM & na & [26] \\
\hline S. masoni & $\begin{array}{l}\text { Alpaca, llama, } \\
\text { guanaco }\end{array}$ & Argentina, Peru & Skeletal muscle & $\begin{array}{l}\text { Ge, Mic, } \\
\text { TEM, PCR }\end{array}$ & na & [14] \\
\hline \multirow[t]{8}{*}{ Sarcocystis sp. } & Guanaco & Chile & Skeletal muscle & Ge & $37(33 / 89)$ & \multirow[t]{3}{*}[32]{} \\
\hline & Llama & Chile & Skeletal muscle & $\mathrm{Ge}$ & $100(28 / 28)$ & \\
\hline & Alpaca & Uruguay & Skeletal muscle & Ge & (4/na) & \\
\hline & Llama & Bolivia & Skeletal muscle & Ge & 34 (na/1196) & [15] \\
\hline & Alpaca & Australia & Skeletal muscle & Ge, His, TEM & $100(1 / 1)$ & [17] \\
\hline & Llama & Argentina & Serum & IFAT & $96(295 / 308)$ & [37] \\
\hline & Alpaca & Peru & Serum & ELISA & $90(844 / 941)$ & [34] \\
\hline & Guanaco & Argentina & $\begin{array}{l}\text { Heart, skeletal } \\
\text { muscle, tongue }\end{array}$ & Ge & $67(8 / 12)$ & {$[56]$} \\
\hline
\end{tabular}

Abbreviations: G gross examination, His histology, IFAT indirect fluorescent antibody test, Mac macroscopic, Mic, microscopic/microscopy, na not available/ applicable, TEM transmission electron microscopy

${ }^{a}$ The name used by the authors 
Table 3 Experimental studies on Sarcocystis spp. infecting South American camelids

\begin{tabular}{|c|c|c|c|c|c|c|}
\hline Species of Sarcocystis ${ }^{a}$ & Geographical location & Experimental animal & $\begin{array}{l}\text { No. of animals } \\
\text { infected }\end{array}$ & $\begin{array}{l}\text { Infective tissue/ } \\
\text { material used }\end{array}$ & Infective dose & Reference \\
\hline \multirow[t]{7}{*}{ S. aucheniae } & Peru & Dog & 18 & Alpaca meat & $100 \mathrm{Mac}$ & {$[45]$} \\
\hline & Peru & Dog & 5 & Alpaca meat & $400 \mathrm{Mac}$ & [30] \\
\hline & Peru & Dog & 18 & Alpaca meat & 180-200 Mac & [47] \\
\hline & Peru & Dog & 13 & Llama meat & $200 \mathrm{~g}$ meat & {$[46]$} \\
\hline & Peru & Dog & 12 & Llama meat & 150-200 Mac & {$[43]$} \\
\hline & Peru & Dog & 26 & Alpaca, Ilama meat & $500 \mathrm{Mac}$ & [31] \\
\hline & Bolivia & Dog, cat & 1,1 & Llama meat & & {$[26]$} \\
\hline \multirow[t]{2}{*}{ S. lamacanis } & Peru & Alpaca & 63 & Sporocyst & $\begin{array}{l}1 \times 10^{3} \\
2.5 \times 10^{3} \\
5 \times 10^{3}\end{array}$ & [23] \\
\hline & Peru & Alpaca & 7 & Sporocyst & $3 \times 10^{4}$ & [24] \\
\hline S. guanicoecanis & Chile & Dog, cat & 4,4 & Guanaco meat & $250 \mathrm{~g}, 50 \mathrm{~g}$ meat & {$[22]$} \\
\hline
\end{tabular}

Abbreviation: Mac macrocysts

${ }^{\text {a }}$ The name used by the authors

that $18 S$ rRNA gene sequences of macroscopic sarcocysts had a sequence homology of $98-99 \%$ with those of previously published sequences of $S$. aucheniae from SACs $[13,14,16,27]$.

\section{Microscopic sarcocysts (S. masoni)}

In 2016, More et al. [14] described the first ultrastructure of a microscopic sarcocyst ( $S$. masoni) found in SACs. Microscopic sarcocysts can measure up to $800 \mu \mathrm{m}$ in length and 35-95 $\mu \mathrm{m}$ in width, with a wall thickness of $2.5-3.5 \mu \mathrm{m}$. The cyst wall harbors conical to cylindrical villar protrusions with several microtubules and each villar protrusion consists of 11 or more rows of knob-like projections. Bradyzoites measure $11-14 \times 2,0-3.5 \mu \mathrm{m}$ in size and contain numerous micronemes and amylopectin granules. Molecular studies targeting full-length $18 \mathrm{~S}$ RNA gene sequencing revealed that this parasite had 95-96\% identity with those of other Sarcocystis spp. available in the GenBank database [14].

\section{Life-cycle of Sarcocystis spp.}

Although the precise life-cycle of Sarcocystis spp. in SACs is not completely known, a general life-cycle of a Sarcocystis spp. is given in Fig. 2. A camelid (intermediate) host becomes infected with Sarcocystis by ingesting sporulated oocysts or sporocysts from the environment $[25,28]$. Each sporocyst contains four sporozoites which are liberated in the digestive tract (following exposure to trypsin or bile) and move to penetrate endothelial cells of blood vessels where they undergo asexual multiplications (schizogony) [1, 29]. Schizonts of Sarcocystis spp. multiply by endopolygeny which results in budding of merozoites at the surface of the schizont. Following a few generations of schizogony (depending on Sarcocystis spp.), a large number of merozoites are produced which migrate to muscles through blood [1]. Merozoites develop into sarcocysts inside parasitophorous vacuoles (made from host cell plasma membrane to protect sarcocysts from host cell defense mechanisms) in myocytes which contain millions of infective bradyzoites [1, 25]. A
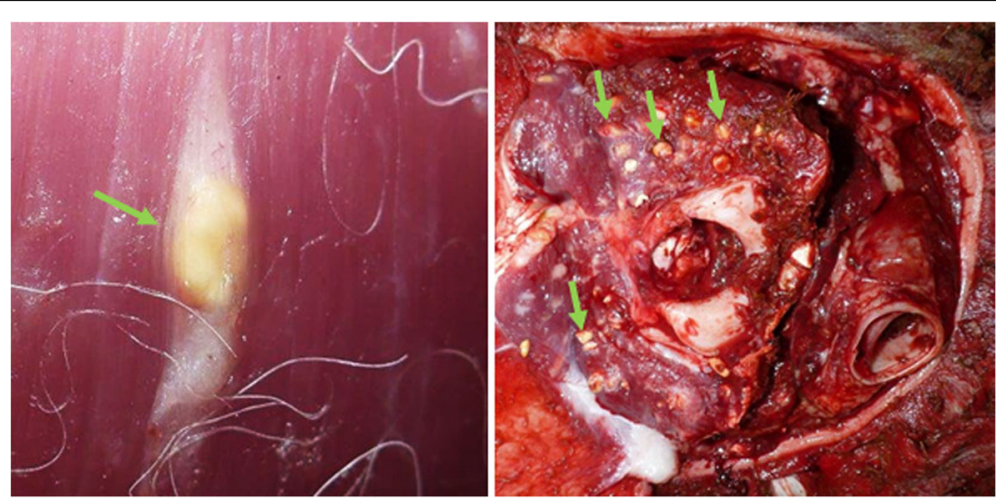

Fig. 1 Macroscopic sarcocysts (arrows) in skeletal muscles of alpaca 


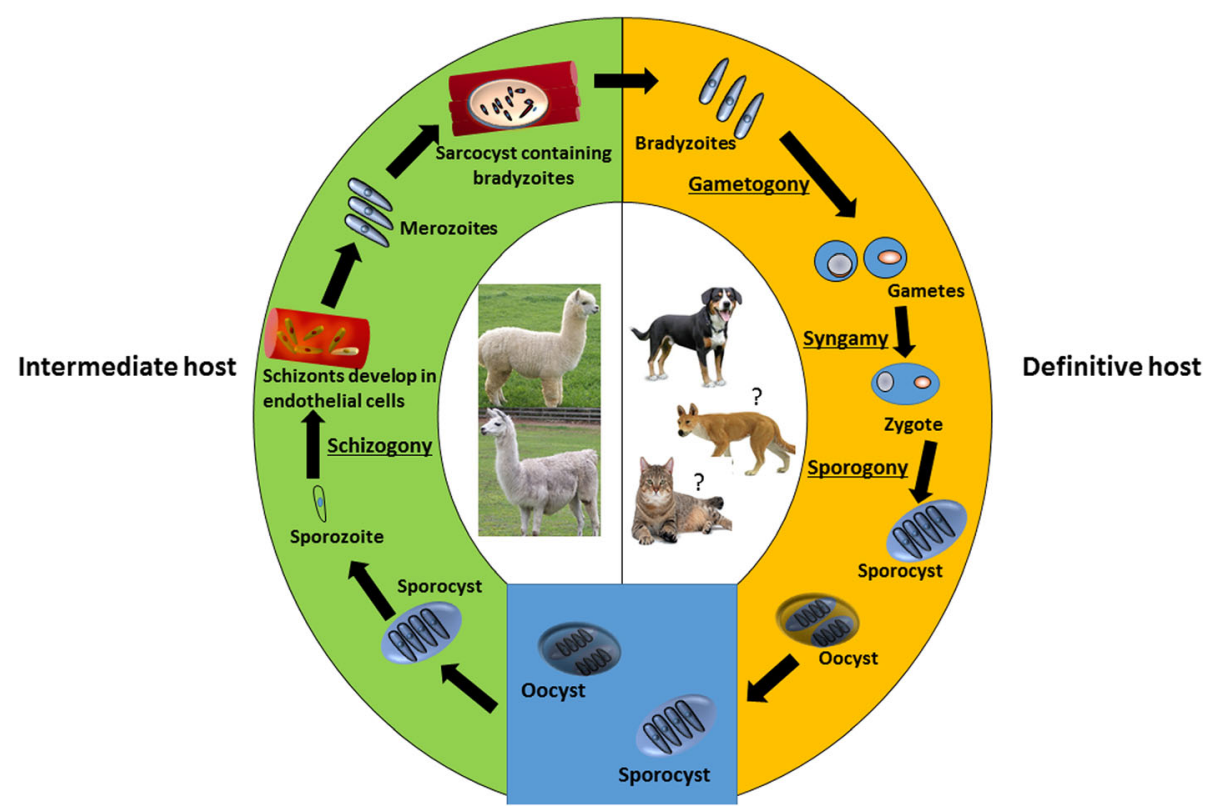

Fig. 2 Life-cycle of Sarcocystis spp. in South American camelids

major structural difference between merozoites and bradyzoites of all Sarcocystis spp. is the absence of rhoptries in merozoites [1]. The number of generations (cycles) of Sarcocystis schizonts (schizogony) and their exact location in the camelid host remains elusive. However, four generation of schizonts have been reported for $S$. cruzi which first appear within endothelial cells of small arteries while subsequent generations are found in arterioles, and then capillaries and veins in various parts of the body until the last generation which develops in muscles [1].

A canid (definitive) host acquires infection following the ingestion of infected meat containing sarcocysts. Bradyzoites are released from the cyst and invade intestinal epithelial cells and undergo gametogony (sexual reproduction) which results in the formation of macrogametes and microgametes. Finally, macro- and micro-gametes fuse to form a zygote in the lamina propria of the small intestine of the definitive host and develop into the oocyst. Oocysts have delicate membrane, which frequently ruptures, releasing sporocysts (which thus can be free, or still encapsulated) in feces and may contaminate food and water consumed by intermediate hosts (e.g. SACs) $[1,25,29]$.

A number of studies have been conducted to establish the definitive host(s) of Sarcocystis spp. that infect SACs (Table 3). Various potential definitive hosts, including dogs and cats, were fed with alpaca, llama and/or guanaco meat containing macroscopic sarcocysts, and following a period of time, feces were examined for the presence of sporocysts [22, 26]. To date, only dogs (fed with infected camelid meat) have been found to produce sporocysts $(14.6-15.0 \times 10.4-10.6 \mu \mathrm{m})$ in their feces, with variable prepatent (9-16 days) and patent (19-61 days) periods [22, 26, 30,31]. These studies indicate that the dog is the potential definitive host for S. aucheniae, the macroscopic cyst forming species. However, the sporocyst burden and prepatent periods in dogs could vary depending on the size of the macrocyst they receive. For instance, the puppies that received smaller size (1-3 $\mathrm{mm}$ ) macrocysts shed significantly more sporocysts with a shorter prepatent period (12 days), compared to those (16 days prepatent period) which received larger (> 5 $\mathrm{mm}$ ) macrocysts [31]. The definitive host for S. masoni, the microcyst forming species, remains unknown although the dog and other canids have been suggested as the potential definitive host(s) for this parasite [14].

\section{Epidemiology of sarcocystosis in SACs}

Very few studies have been undertaken to understand the epidemiology of sarcocystosis in SACs. Table 2 summarizes key studies on the prevalence of Sarcocystis spp. in these animals. Natural infections with Sarcocystis spp. in SACs are mostly asymptomatic $[8,15,32]$; however, significant pathology could be observed in affected tissues [17]. The prevalence of Sarcocystis infections in SACs has been estimated, including alpacas (90-100\%), llamas (34-100\%) and guanacos (37-100\%) (Table 2). However, caution must be taken when comparing these prevalence figures due to differences in the sampling frame, diagnostic methods used, animal age, type of tissue(s) analyzed and the number of samples used in these studies. To date, no epidemiological information is available for sarcocystosis from vicunas. 
Poor sanitation and the presence of pastoral dogs are considered as risk factors for sarcocystosis in SACs. For instance, a higher prevalence (50\%) of sarcocystosis was observed in llamas kept under poor sanitary conditions and in the presence of pastoral dogs, compared to those (23 and 26\%) kept at different localities but under good sanitary conditions and in the absence of pastoral dogs [8]. These results indicate that herd management practices could greatly impact the exposure of camelids to Sarcocystis. In fact, infective sporocysts of Sarcocystis spp. are passed in faeces of the definitive host and they could remain infective for many months. Furthermore, their maturation and infectivity are not dependent on weather conditions unlike many other coccidian parasites [33] which could explain high infection rates in llamas kept under poor sanitary conditions [8].

Location and feeding practices have been found to affect the prevalence of sarcocytosis in SACs. For example, the prevalence of macroscopic sarcocysts in commercially slaughtered llamas from Bolivia varied between 23\% (2007) and 50\% (2011) with an overall prevalence of 34\% [15]. In another study, a high prevalence (100\%) of Sarcocystis was observed in llamas slaughtered in Chile [32] (Table 2). This difference in the infection rates could be due to variation in geoclimatic location and potentially feeding practices as a higher prevalence of Sarcocystis was reported in guanacos grazing on pastures than those from forested areas [32]. The high prevalence in the former group was possibly due to frequent contact of these animals with dogs used for shepherding - the potential definitive hosts for Sarcocystis [32]. However, it has been demonstrated recently in Argentina that sarcocystosis in llamas remained unaffected by climate, altitude or pasture characteristics [8] which warrant for further studies.

Age has been shown to be a risk factor for Sarcocystis infections in llamas and alpacas as the older animals harbor sarcocysts more frequently than the younger ones $[8,15,34]$ as they have been exposed to potentially infected pasture for longer. Likewise, females and longhaired llamas had higher infection rates than males and short/intermediate-haired llamas, respectively, indicating that gender and breed could also contribute to developing sarcocysts in SACs [15]. Gestation and parturition, especially the first parturition may negatively impact immunity in female camelids which could contribute to developing sarcocysts in these animals. However, in a recent study male gender was regarded as a risk factor for developing sarcocystosis in llamas [8] which requires further investigation.

SACs are most likely infected by ingestion of food and water contaminated with sporocysts from dog feces. Thus, disrupting the Sarcocystis life-cycle between SACs and the potential definitive hosts such as dogs could be an effective strategy for controlling sarcocystosis in
SACs. The lactogenic transfer of Sarcocystis via milk or colostrum could be another potential method of transmission in SACs though experimental infection studies failed to transfer Sarcocystis spp. from cows to calves via these methods [1]. Transport hosts (e.g. birds) have been reported to disseminate sporocysts for some Sarcocystis spp. [35], although the role of transport host remains to be established for Sarcocystis spp. infecting SACs.

\section{Pathogenesis of sarcocystosis in SACs}

Very little is known about the pathogenesis of sarcocystosis in SACs. Generally, the number and distribution of sarcocysts in intermediate hosts depend on several factors, including the number of sporocysts ingested, the immune status of the host and Sarcocystis spp. involved $[1,28,36]$. However, none of these factors have yet been explored fully for sarcocystosis in SACs.

Sarcocystosis is usually asymptomatic in SACs, though multiple superficial abscesses in the neck have been observed occasionally. Fatal clinical cases ascribed to macroscopic sarcocystosis have also been reported. For instance, eosinophilic myositis was reported in the USA in an alpaca naturally infected with Sarcocystis [18] and it exhibited clinical signs, including recumbency, hypothermia and non-responsiveness to external stimuli, dyspnea, marked muscle tremors, reduced milk production and abortion. At post-mortem, white macroscopic sarcocysts $(8 \times 3 \mathrm{~mm})$ in skeletal muscles and hemorrhages in myofibers were observed throughout the carcass [18]. A similar case of necrotizing and histiocytic myositis was reported from an alpaca in Australia [17]. The aspirate analysis of subcutaneous abscess-like structures along the head and cervical region revealed the presence of large numbers of eosinophils. Examination of hematological parameters showed peripheral eosinophilia, hyperproteinemia and hyperglobulinemia. At post-mortem, multiple foci of caseating, pale, white, streaking lesions were noted on the cranial and cervical musculature. Histologically, the infected tissues were characterized by multifocal caseous necrosis associated with histiocytes, giant cells and lymphocytes [17]. A significant destruction and necrosis in tissues could be explained by rapid multiplication of asexual developmental stages, though it requires further investigation. However, localized tissue necrosis alone may not be enough to cause severe illness or death seen in large animals [1]. Overall these studies indicate that Sarcocystis could be highly pathogenic or even fatal in SACs.

Recently, the effect of microscopic sarcocysts was studied in young alpacas, experimentally infected with sporocysts [23]. The infected alpacas showed decreased body weight gain and hematocrit levels compared to control groups. A high mortality (92\%) was observed in alpacas infected with a high dose of sporocysts [23]. 
Histological examination of cardiac muscle revealed that microscopic sarcocysts were located only in myocytes and not in Purkinje cells and they did not cause any interruption in the conduction of electrical impulses through the myocardium [24].

Overall these studies indicate that Sarcocystis spp. can account for significant pathology in SACs, although the infection usually remains subclinical or asymptomatic. Further studies are required to understand the pathogenesis of both macro- and microscopic sarcocystosis and their impact on musculoskeletal and cardiac function, immunity and productivity of SACs, especially in terms of animal welfare and economic importance.

\section{Diagnosis of sarcocystosis in SACs}

There are no standard criteria or commercial tests available for the diagnosis of sarcocystosis in SACs. The identification of sarcocysts in muscles of alpacas and llamas at necropsy has been used as the sole definitive diagnostic method in most of the studies (Table 2). The disease can be diagnosed based on the elimination of other parasites with similar clinicopathology and an evaluation of epidemiological information. However, the diagnosis of acute sarcocystosis is challenging as the disease may be asymptomatic or generalized in nature, with no specific signs and it is unlikely that sarcocysts would be detected in tissues at this stage.

A few studies have utilized serological methods for the diagnosis of sarcocystosis in SACs. For instance, a serological test was developed to diagnose anti-Sarcocystis antibodies in llama serum, where soluble antigen was isolated from macrocysts collected from alpacas naturally infected with $S$. aucheniae [12]. However, due to its low sensitivity and specificity ( $65 \%$ for each), it was concluded that the test was unsuitable for the detection of sarcocystosis in individual animals [12]. Subsequently, an indirect fluorescent antibody test (IFAT) was developed to determine the seroprevalence of sarcocystosis in llamas [37]. Using bradyzoite-derived antigens from $S$. aucheniae as well as $S$. cruzi (cause sarcocystosis in cattle), the test allowed the detection of anti-Sarcocystis antibodies in $96 \%$ of llama serum tested. However, cross-reactivity was also observed between Sarcocystis spp. since two different types of bradyzoites ( $S$. aucheniae from llama and S. cruzi from cattle) were used [37], thereby making this test unsuitable for species identification. Recently, Romero et al. [8] developed an indirect enzyme-linked immunosorbent assay (ELISA) to detect anti-Sarcocystis antibodies in serum from llamas. They used the $\mathrm{Sa} 23$ protein antigen which is a $23 \mathrm{kDa}$ soluble immunogenic fraction of $S$. aucheniae macrocysts. Hence, these studies indicate that serological diagnosis of sarcocystosis in SACs is possible; however, none of the studies defined the precise nature of antigens used or verified serological diagnosis with molecular or histopathological diagnoses.

A variety of molecular methods have been developed for assessing the genetic diversity as well as for the diagnosis of Sarcocystis spp. in animals [16, 38, 39]. The first molecular identification of macrocysts of $S$. aucheniae in alpacas was made in Australia where the $18 S$ rRNA gene fragment was amplified using conventional polymerase chain reaction (PCR) [27], and the phylogenetic analyses of the $18 S$ rRNA sequences revealed that these were different from those of Sarcocystis spp. that infect other ruminants. Subsequent studies also amplified $18 S$ rRNA gene from macrocysts of $S$. aucheniae collected from llamas [16] and guanacos [13], and these $18 S$ rRNA sequences from different SAC species were homologous, suggesting that $S$. aucheniae infects three species (i.e. alpacas, llamas and guanacos) of SACs and can potentially be diagnosed using common molecular method(s). Molecular diagnosis from sarcocysts is invaluable in identifying Sarcocystis at the species level; however, this method may have little value in the early diagnosis of sarcocystosis in SACs as the DNA is isolated from a developed cyst. Contrarily, the detection of Sarcocystis DNA from body fluids (such as blood) could be a much more valuable diagnostic tool for early diagnosis, particularly for the identification of microcyst-forming Sarcocystis spp. Recently, a semi-nested PCR was developed to detect the DNA of $S$. aucheniae from blood in llamas [38]. This method allowed the detection of as few as 100 bradyzoites per $\mathrm{ml}$ of blood. However, this test was not field-validated for the diagnosis of Sarcocystis spp. from the blood of naturally or experimentally infected SACs.

\section{Zoonosis and food safety with sarcocystosis}

Currently known Sarcocystis spp. with zoonotic potential are S. hominis, S. heydorni and S. suihominis, all of which use humans as definitive host; the former two utilize cattle while S. suihominis uses pigs as intermediate hosts $[29,40]$. S. nesbitti is another important Sarcocystis spp. which can infect humans (intermediate host) following the ingestion of food or water contaminated with reptile feces and snakes are considered as the potential definitive hosts for this parasite [41, 42]. It has been suggested that Sarcocystis-infected meat contains a cyst-derived neurotoxin called sarcocystin which can cause gastroenteritis, diarrhea, nausea, shivering and respiratory problems in human if the uncooked infected meat is consumed $[6,16,29]$. Although SAC meat infected with Sarcocystis spp. can cause significant pathology in dogs and cytotoxicity in rabbits, their zoonotic potential has not been established [6, 43, 44].

Physical methods of treating infected meat have been used to inactivate the protein toxin and the viability of 
sarcocysts. For example, llama meat naturally infected with $S$. aucheniae macrocysts was treated with different physical methods such as boiling $\left(100{ }^{\circ} \mathrm{C}\right.$ for $\left.10 \mathrm{~min}\right)$, baking $\left(105{ }^{\circ} \mathrm{C}\right.$ for $\left.65 \mathrm{~min}\right)$, freezing $\left(-20{ }^{\circ} \mathrm{C}\right.$ for 10 days) and frying, and then was fed to young dogs $[45,46]$. The dogs that received treated meat did not pass any sporocysts in their feces whereas those who received untreated meat did pass sporocysts. In experimental rabbits, frozen meat consumption led to the development of moderate signs of toxicity (e.g. prostration, dyspnea, miosis, hyperthermia, diarrhea). Similarly, freezing $\left(-18{ }^{\circ} \mathrm{C}\right.$ to $-24{ }^{\circ} \mathrm{C}$ ) for five days or cooking (above $60{ }^{\circ} \mathrm{C}$ ) was shown to be effective in inactivating sarcocysts in guanaco meat; however, refrigeration (for 30 days) was ineffective [22]. These results indicate that boiling, baking, frying and to some extent freezing can neutralize the viability and toxicity of macrocysts.

Chemical methods such as hot and cold smoking, dry curing and marination have also been used to detoxify llama and alpaca meat naturally infected with sarcocysts of $S$. aucheniae [43, 45]. All these methods were found effective in eliminating the viability of sarcocysts as dogs did not pass any sporocysts after receiving the chemically treated meat [43, 45]. However, variable toxicity results were observed in rabbits that received chemically treated meat $[43,45,47]$. This indicates that not all chemically-treated methods are effective in neutralizing the toxicity of sarcocysts.

\section{Control and prevention of sarcocystosis in SACs}

There is no vaccine available to protect camelids or other domestic animals against sarcocystosis [1, 19, 29]. Immunization studies in domestic animals such as cattle, sheep, goats and pigs have shown that animals inoculated with Sarcocystis sporocysts were protected against a challenge dose of the parasite that normally would have been lethal $[1,48,49]$. This indicates that a vaccine could potentially be developed against Sarcocystis spp. of SACs and other domestic animals. However, a thorough understanding of immune responses of animals against Sarcocystis spp. is a pre-requisite for the vaccine development which has been a totally untouched area of research in SACs to date.

Anticoccidial drugs have been used to treat sarcocystosis in both definitive and intermediate hosts. For example, a severe form of sarcocystosis was prevented when camels experimentally infected with Sarcocystis sp. were treated with Amprolium ${ }^{\odot}$ [50]. Other drugs such as salinomycin and halofuginone have also been used to reduce or prevent acute sarcocystosis in domestic animals infected with Sarcocystis spp. [1, 19, 51]. Notably, such drugs could be effective only in treating intestinal stages of Sarcocystis during the acute phase, which is almost impossible to detect under field conditions. Furthermore, such antiparasitic drugs not only could be toxic to SACs [52] but may have no value in treating sarcocysts developed in muscles. Therefore, prevention is the only practical solution to control sarcocystosis in SACs.

South American camelids develop sarcocystosis by ingesting sporocysts from a contaminated environment arising from infected faeces of carnivores. Although the life-cycle of Sarcocystis in SACs is not precisely known, the following steps could be followed to potentially disrupt the life-cycle and control of sarcocystosis in SACs: (i) domestic and wild carnivores should be excluded from animal housing and from feed, water, and bedding for SACs; (ii) farm dogs should be prevented from defecating on pastures and animal food/bedding storage sites; (iii) uncooked/untreated camelid meat should not be fed to dogs as it may contain sarcocysts; and (iv) alpaca and llama carcasses and camelid foetal/placental material should be kept away from dogs and wild carnivores by burying or incineration.

\section{Research gaps and future implications}

Currently, the classification of Sarcocystis spp. infecting SACs is primarily based on the morphology of cyst wall of sarcocysts. For example, the cyst wall of S. aucheniae is characterized by cauliflower-like villar protrusions while that of $S$. masoni harbors conical to cylindrical villar protrusions. However, it is important to consider that physical features such as the type of cyst wall or cyst size may vary with the age/development of the cyst, location and type of the host cell, and tissue processing/fixation method, therefore caution must be taken while describing a Sarcocystis sp. based on morphological characters alone $[1,2,36]$. Furthermore, most of the studies describing the structure of sarcocysts have examined only a small number of cysts to describe new species of Sarcocystis in SACs $[13,14]$. Thus, it is imperative to use molecular tools besides morphological characterization, with a large sample size for the robust and authentic taxonomy of Sarcocystis spp. that infect SACs.

To date, only dogs have been found to be a definitive host of Sarcocystis spp. that infect SACs. However, the role of wild/feral canids as definitive hosts of these species of Sarcocystis should be not be ignored as sarcocysts have been reported in other camelids (e.g. camels) in the absence of their known definitive host (dogs) [53]. Furthermore, the movement of SACs from their native South America to new geographical locations such as Australia and the USA, and the presence of Sarcocystis in camelids in these locations highlight the possibility of an involvement of new definitive host(s) such as dingoes (in Australia) under different climatic conditions. Future studies are required to establish the types of definitive host(s) of different species of Sarcocystis that infect SACs, thereby increasing our understanding about 
sarcocystosis in these animals and helping to design effective control strategies.

The lack of availability of a standard diagnostic test has impeded our ability to fully understand the epidemiology, clinical pathology and public health significance of sarcocystosis in SACs. Furthermore, the assessment of sensitivity and specificity of the new tests is challenging due to the lack of validated techniques for the diagnosis of sarcocystosis in SACs. A validated test that could allow the early detection of Sarcocystis from blood in SACs would be a benchmark for the diagnosis of sarcocystosis. Studies indicate that early diagnosis of sarcocystosis in SACs is feasible with serological methods, although a high inter-species cross-reactivity exists among Sarcocystis spp. infecting various ruminant species $[8,37]$. Thus, it is important to consider the following factors for successful development and implementation of a serological test, including (i) the precise nature of antigens used; (ii) the type of antibodies (e.g. IgG, IgM) detected in serum; (iii) the correlation concordance between premortem serological and post-mortem histopathological diagnosis; and (iv) the sensitivity and specificity of the assay. Furthermore, a serological test for the diagnosis of sarcocystosis may require large numbers of highly purified parasites. The possible sources of purified parasites could be experimentally infected alpacas and llamas and in vitro cultivation of the parasite [54]. Molecular diagnosis of Sarcocystis spp. from blood could be another potential method for the early detection of Sarcocystis in SACs [38]. Studies have shown that merozoites could be detected in buffy coat preparations from cattle experimentally infected with Sarcocystis sp. as early as day 16 post-infection [55]. Although this method is tedious and not practical for routine diagnosis of sarcocystosis, it highlights the potential implication of PCR-based detection of Sarcocystis DNA from blood of SACs.

There is a paucity of information on the developmental stages (e.g. merozoites, macrogametes, microgametes etc.) of the parasite in both the camelid and definitive hosts. Although some asexual stages of $S$. aucheniae have been described in vitro [54], experimental infection studies are required to better understand the developmental biology and pathogenesis of Sarcocystis spp. in SACs as well as their definitive host(s).

\section{Conclusions}

This article highlights the importance of sarcocystosis and comprehensively reviews the existing knowledge on sarcocystosis in SACs across the globe. SACs serve as important intermediate hosts for at least two morphologically and molecularly distinct Sarcocystis spp., $S$. aucheniae and S. masoni, that form macroscopic and microscopic sarcocysts, respectively. Macroscopic sarcocysts commonly occur in skeletal muscles while cardiac muscles appear to be the predilection site of microcysts. Generally, sarcocystosis remains asymptomatic, although fatal clinical cases have been reported in SACs. Age, poor sanitary conditions and the presence of dogs are some of the risk factors for the development of sarcocystosis in SACs. Several diagnostic tests have been used to diagnose sarcocystosis in SACs but a diagnostic method for an early detection of infection with Sarcocystis spp. is yet to be developed. Currently, no effective methods are available for the treatment and control of sarcocystosis in SACs. Although this article has provided a detailed analysis of the existing body of knowledge on sarcocystosis in SACs, a number of other aspects of this disease in alpacas and llamas still require further work to enhance our understanding about the impact of sarcocystosis on animal health in terms of productivity, weight gain, reproductive efficiency, wool production, immunity, musculoskeletal functioning, susceptibility to other diseases and economic losses.

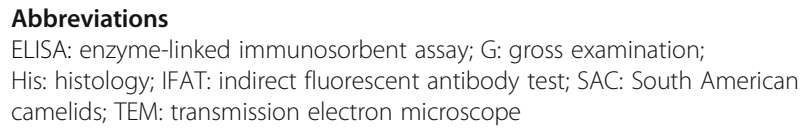

Availability of data and materials

All data used in the manuscript were from the published literature. The data supporting the conclusions have been provided within the article.

\section{Authors' contributions}

MAS searched literature and databases, systematically arranged the information/ data and drafted the manuscript. AJ conceived the idea of this review and critically edited and revised the manuscript. JV and MHR commented on the structure of manuscript and provided critical intellectual input. All authors read and approved the final manuscript.

\section{Ethics approval and consent to participate} Not applicable.

\section{Consent for publication}

Not applicable.

\section{Competing interests}

The authors declare that they have no competing interests.

\section{Publisher's Note}

Springer Nature remains neutral with regard to jurisdictional claims in published maps and institutional affiliations.

\section{Author details}

${ }^{1}$ Department of Veterinary Biosciences, Faculty of Veterinary and Agricultural Sciences, The University of Melbourne, Werribee, Victoria 3030, Australia. ${ }^{2}$ Cria Genesis, PO Box 406, Ocean Grove, Victoria 3226, Australia. 


\section{Received: 15 January 2018 Accepted: 26 February 2018} Published online: 06 March 2018

\section{References}

1. Dubey J, Calero-Bernal R, Rosenthal B, Speer C, Fayer R. Sarcocystosis of animals and humans. 2nd ed: Taylor and Francis Group: CRC Press; 2015

2. Tenter AM. Current research on Sarcocystis species of domestic animals. Int J Parasitol. 1995;25:1311-30.

3. Wernery U, Kinne J, Schuster RK, editors. Camelid infectious disorders. Paris: (OIE) World Organisation for Animal Health; 2014.

4. Sazmand A, Joachim A. Parasitic diseases of camels in Iran (1931-2017) - a literature review. Parasite. 2017;24:1-15.

5. Fitzgerald SD, Janovitz EB, Kazacos KR, Dubey J, Murphy DA. Sarcocystosis with involvement of the central nervous system in lambs. J Vet Diagn Invest. 1993;5:291-6.

6. Leguía G. The epidemiology and economic impact of llama parasites. Parasitol Today. 1991;7:54-6.

7. Frank E. Situación actual de los camélidos sudamericanos en Argentina. Proyecto de cooperación técnica en apoyo a la crianza y aprovechamiento de los camélidos sudamericanos en la Región Andina: Food and Agriculture Organization; 2005. http://www.produccion-animal.com.ar/produccion_de_ camelidos/camelidos_general/162-situacion.pdf. Accessed 19 Nov 2017

8. Romero S, Carletti T, Franco CD, Moré G, Schnittger L, Florin-Christensen M. Seropositivity to Sarcocystis infection of llamas correlates with breeding practices. Vet Parasitol. 2017;10:65-70.

9. McGregor B. Production, attributes and relative value of alpaca fleeces in southern Australia and implications for industry development. Small Rumin Res. 2006;61:93-111.

10. Mamani-Linares LW, Gallo CB. Meat quality, proximate composition and muscle fatty acid profile of young llamas (Lama glama) supplemented with hay or concentrate during the dry season. Meat Sci. 2014;96:394-9.

11. Alpaca industry fact sheet. Australian Alpaca Association. 2014. http://qldnsw. alpaca.asn.au/aaw/news/industry_fact_sheet_2014.pdf. Accessed 20 Nov 2017.

12. Viscarra R, Rushton J, González A, López T. Validation of a serological test for sarcocystiosis in llamas found in the Bolivian High Andes. In: Proceedings of the 10th International Symposium on Veterinary Epidemiology and Economics; 2003. http://www.sciquest.org.nz/node/63144. Accessed 20 Nov 2017.

13. Regensburger C, Gos M, Ctibor J, Moré G. Morphological and molecular characteristics of Sarcocystis aucheniae isolated from meat of quanaco (Lama guanicoe). J Food Qual Hazards Control. 2015;2:118-21.

14. More G, Regensburger C, Gos ML, Pardini L, Verma SK, Ctibor J, et al. Sarcocystis masoni, n. sp. (Apicomplexa: Sarcocystidae), and redescription of Sarcocystis aucheniae from llama (Lama glama), guanaco (Lama guanicoe) and alpaca (Vicugna pacos). Parasitology. 2016;143:617-26.

15. Rooney A, Limon G, Vides H, Cortez A, Guitian J. Sarcocystis spp. in llamas (Lama glama) in southern Bolivia: a cross-sectional study of the prevalence, risk factors and loss in income caused by carcass downgrades. Prev Vet Med. 2014:116:296-304.

16. Carletti T, Martin M, Romero S, Morrison DA, Marcoppido G, FlorinChristensen M, et al. Molecular identification of Sarcocystis aucheniae as the macrocyst-forming parasite of llamas. Vet Parasitol. 2013;19:396-400

17. Gabor M, Gabor LJ, Srivastava M, Booth M, Reece R. Chronic myositis in an Australian alpaca (Llama pacos) associated with Sarcocystis spp. J Vet Diagn Invest. 2010;22:966-9.

18. La Perle KMD, Silveria F, Anderson DE, Blomme EAG. Dalmeny disease in an alpaca (Lama pacos): sarcocystosis, eosinophilic myositis and abortion. J Comp Pathol. 1999;121:287-93.

19. Chhabra MB, Samantaray S. Sarcocystis and sarcocystosis in India: status and emerging perspectives. J Parasit Dis. 2013;37:1-10.

20. Brumpt E. Précis de parasitologie. 2nd ed. Paris: Masson et Cie; 1913.

21. Quiroga D, Lombardero O, Zorrilla R. Sarcocystis tilopodi n. sp. en guanacos (Lama guanicoe) de la República Argentina. Gac Vet. 1969;31:67-70.

22. Gorman T, Alcaíno H, Muñuz H, Cunazza C. Sarcocystis sp. in quanaco (Lame guanicoe) and effect of temperature on its viability. Vet Parasitol. 1984;15:95-101.

23. Chávez V, Leyva V, Panez L, Ticona S, García V, Pezo C. Sarcocistiosis y la eficiencia productiva de la alpaca. Rev Investig Vet del Perú. 2008;19(2):160-7.

24. Bowler B, Grandez R. Electrocardiographical parameters in alpacas infected with Sarcocystis lamacanis. Int J Appl Res Vet Med. 2008;6:87-92.

25. Abdel-Ghaffar F, Mehlhorn H, Bashtar AR, Al-Rasheid KAS, Sakran T, ElFayoumi H. Life cycle of Sarcocystis camelicanis infecting the camel (Camelus dromedarius) and the dog (Canis familiaris), light and electron microscopic study. Parasitol Res. 2009;106:189-95.

26. Schnieder T, Kaup F, Drommer W, Thiel W, Rommel M. Fine structure and development of Sarcocystis aucheniae in Ilamas. Z Parasitenkd. 1984;70:451-8.

27. Holmdahl OJM, Morrison DA, Ellis JT, Huong LTT. Evolution of ruminant Sarcocystis (Sporozoa) parasites based on small subunit rDNA sequences. Mol Phylogenet Evol. 1999;11(1):27-37.

28. Saeed MA, Vaughan J, Jabbar A. An update on sarcocystosis in one-humped camels (Camelus dromedarius). Parasitology. 2018; https://doi.org/10.1017/ S0031182018000239.

29. Poulsen CS, Stensvold CR. Current status of epidemiology and diagnosis of human sarcocystosis. J Clin Microbiol. 2014;52:3524-30.

30. Zacarías S, Sam T, Ramos D, Lucas A, Lucas L. Técnicas de aislamiento y purificación de ooquistes de Sarcocystis aucheniae a partir de intestino delgado de perros experimentalmente infectados. Rev Investig Vet Perú. 2013;24:396-403.

31. Cornejo B, Chávez V, Leyva V, Falcón P, Panez L, Ticona S. Relación entre el tamaño de los macroquistes de Sarcocystis aucheniae y su viabilidad en Canis familiaris. Rev Investig Vet Perú. 2007:18:76-83.

32. Schnake FG, Perez W, Paulsen P, Konig HE. Sarcocystosis in New World camelids in Chile and Uruguay. Fleischwirtschaft. 2016;96:206-8.

33. Savini G, Robertson I, Dunsmore J. Viability of the sporocysts of Sarcocystis cruzi after exposure to different temperatures and relative humidities. Vet Parasitol. 1996;67:153-60

34. Castro C, Sam T, López U, González Z, Silva I. Evaluación de la edad como factor de riesgo de seropositividad a Sarcocystis sp. en alpacas. Rev Investig Vet Perú. 2004;15(1):83-6.

35. Markus MB. Flies as natural transport hosts of Sarcocystis and other coccidia. J Parasitol. 1980;66:361-2.

36. Fayer R, Esposito DH, Dubey JP. Human infections with Sarcocystis species. Clin Microbiol Rev. 2015;28(2):295-311.

37. More G, Pardini L, Basso W, Marin R, Bacigalupe D, Auad G, et al. Seroprevalence of Neospora caninum, Toxoplasma gondii and Sarcocystis sp in Ilamas (Lama glama) from Jujuy, Argentina. Vet Parasitol. 2008;155:158-60.

38. Martin M, Franco CD, Romero S, Carletti T, Schnittger L, Florin-Christensen M. Molecular detection of Sarcocystis aucheniae in the blood of llamas from Argentina. Rev Argent Microbiol. 2016;48:200-5.

39. Stojecki K, Karamon J, Sroka J, Cencek T. Molecular diagnostics of Sarcocystis spp. infections. Pol J Vet Sci. 2012;15:589-96.

40. Dubey JP, van Wilpe E, Calero-Bernal R, Verma SK, Fayer R. Sarcocystis heydorni, n. sp. (Apicomplexa: Sarcocystidae) with cattle (Bos taurus) and human (Homo sapiens) cycle. Parasitol Res. 2015;114:4143-7.

41. AbuBakar S, Teoh B-T, Sam S-S, Chang L-Y, Johari J, Hooi P-S, et al. Outbreak of human infection with Sarcocystis nesbitti, Malaysia, 2012. Emerg Infect Dis. 2013:19:1989-91.

42. Lau YL, Chang PY, Tan CT, Fong MY, Mahmud R, Wong KT. Sarcocystis nesbitti infection in human skeletal muscle: possible transmission from snakes. Am J Trop Med Hyg. 2014;90:361-4.

43. Granados Z, Vilca L, Sam T. Saneamiento y detoxificación de carne de llama (Lama glama) infectada con Sarcocystis aucheniae mediante métodos químicos: marinado, ahumado, curado seco y curado húmedo. Rev Investig Vet Perú. 2007;18:57-63.

44. Inga MC, Manchego A, Sandoval N, Burga C, Castro G, Rivera H. Efecto in vitro del extracto proteico de macroquistes de Sarcocytis aucheniae sobre la viabilidad y degranulación de leucocitos de conejo (Oryctologus cuniculus). Rev Invest Vet Perú. 2016;27:333-43.

45. Vilca M, Durán J, Ramos D, Lucas J. Saneamiento y eliminación de la toxicidad de carne de alpaca (Vicugna pacos) con sarcocistiosis mediante ahumado y curado. Rev Investig Vet Perú. 2013;24:537-43.

46. Godoy Z, Vilca L, Gonzáles Z, Leyva V, Sam T. Saneamiento y detoxificación de carne de llama (Lama glama) infectada con Sarcocystis aucheniae mediante cocción, horneado, fritura y congelado. Rev Investig Vet Perú. 2007;18:51-6.

47. Céspedes V, Vilca L, Ramos D, Sam T, Lucas L. Saneamiento y detoxificación de carne de alpaca (Vicugna pacos) con sarcocistosis mediante tratamientos físicos y químicos de uso doméstico. Rev Investig Vet Perú. 2013:24:404-6.

48. Fayer R, Dubey J. Protective immunity against clinical sarcocystosis in cattle. Vet Parasitol. 1984:15:187-201.

49. Ford G. Immunity of sheep to homologous challenge with dog-borne Sarcocystis species following varying levels of prior exposure. Int J Parasitol. 1985;15:629-34 
50. Ishag MY, Majid A, Magzoub A. Isolation of a new Sarcocystis species from Sudanese camels (Camelus dromedarius). Int J Trop Med. 2006;1:167-9.

51. Fayer R. Sarcocystis spp. in human Infections. Clin Microbiol Rev. 2004;17:894-902.

52. Anderson DE. Ionophores: Salinomycin Toxicity in Camelids. Zoo and Wild Animal Medicine. 6th ed. Amsetrdam: Elsevier; 2008. https://veteriankey. com/ionophores-salinomycin-toxicity-in-camelids/. Accessed 29 Nov 2017

53. Woldemeskel M, Gumi B. Prevalence of sarcocysts in one-humped camel (Camelus dromedarius) from southern Ethiopia. J Vet Med. 2001;48:223-6.

54. Uzuriaga S, Sam T, Manchego S, Alvarado S. Desarrollo de estadios asexuales de Sarcocystis aucheniae en cultivo de células. Rev Invest Vet Perú. 2008;19:49-53.

55. Dubey J. Quantitative parasitemia in calves fed Sarcocystis cruzi sporocysts from coyotes. Am J Vet Res. 1982;43:1085-6.

56. Beldomenico PM, Uhart M, Bono MF, Marull C, Baldi R, Peralta JL. Internal parasites of free-ranging guanacos from Patagonia. Vet Parasitol. 2003;118:71-7.

Submit your next manuscript to BioMed Central and we will help you at every step:

- We accept pre-submission inquiries

- Our selector tool helps you to find the most relevant journal

- We provide round the clock customer support

- Convenient online submission

- Thorough peer review

- Inclusion in PubMed and all major indexing services

- Maximum visibility for your research

Submit your manuscript at www.biomedcentral.com/submit 